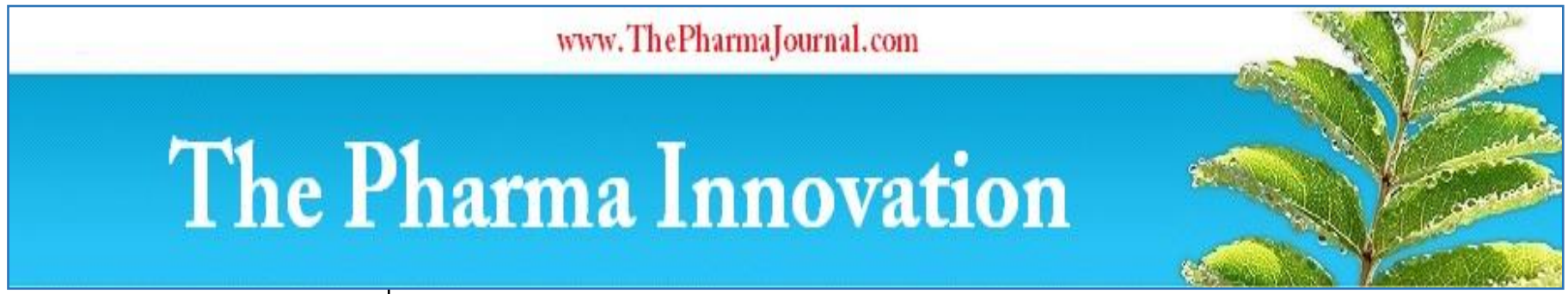

ISSN (E): 2277 - 7695

ISSN (P): 2349-8242

NAAS Rating: 5.03

TPI 2020; 9(6): 36-40

(C) $2020 \mathrm{TPI}$

www.thepharmajournal.com

Received: 18-04-2020

Accepted: 20-05-2020

Disha Negi

Student, Department of Food

Technology, School of Applied

and life Sciences, Uttaranchal

University, Dehradun,

Uttarakhand, India

Prateek Gururan

Assistant Professor, Department

of Food Technology, School of

applied and life Sciences,

Uttaranchal University,

Dehradun, Uttarakhand, India

Mamta Goswami

Student, Department of Food

Technology, School of Applied and life Sciences, Uttaranchal

University, Dehradun,

Uttarakhand, India

Corresponding Author:

Prateek Gururani

Assistant Professor, Department

of Food Technology, School of

Applied and life Sciences,

Uttaranchal University,

Dehradun, Uttarakhand, India

\section{Probiotics: A review}

\author{
Disha Negi, Prateek Gururani and Mamta Goswami
}

DOI: https://doi.org/10.22271/tpi.2020.v9.i6a.4770

\begin{abstract}
Probiotics are live microorganisms that give wellbeing benefits to the host when ingested in satisfactory sums. The strains most every now and again utilized as probiotics incorporate lactic corrosive microorganisms and Bifidobacterium. Probiotics have illustrated critical potential as restorative alternatives for an assortment of illnesses, however the instruments liable for these impacts have not been completely clarified at this point. A few significant mechanisms hidden the hostile impacts of probiotics on different microorganisms incorporate the accompanying: adjustment of the gut microbiota, serious adherence to the mucosa furthermore, epithelium, fortifying of the gut epithelial hindrance furthermore, tweak of the insusceptible framework to pass on an advantage to the host. Aggregating proof exhibits that probiotics speak with the host by design recognition receptors, for example, cost like receptors and nucleotiderestricting oligomerization area containing protein-like receptors, which tweak key flagging pathways, for example, atomic factor-B and mitogen-initiated protein kinase, to upgrade or stifle initiation and impact downstream pathways.
\end{abstract}

Keywords: Probiotics, antimicrobial responses, bifidobacteria, lactobacilli, mechanism of probiotics,

\section{Introduction}

Probiotics has been characterized as live small scale life forms that offer wellbeing enthusiasm to have cells when coordinated to an individual's eating routine in satisfactory sum by food and agriculture organization and World healthorganization. The human gastrointestinal tract support different bacterial networks that contains in excess of 1000 unique species and surpass the quantity of physical and germ cells by multiple times (www.fao.org, 2001) ${ }^{[49]}$.

predominant and subdominant gatherings of gastro intestinal microbiota are strains having a place with Bifidobacterium and Lactobacillus individual (Guarner and Malaglada, 2003) ${ }^{[17]}$. In the wake of having a tireless safe use for over thousand years, probiotics has expanded acknowledgment with respect with it's impact on human wellbeing (Liong, 2011). Frequently the measures set for choice of probiotics incorporate their toleration level to gastrointestinal conditions (gastric and bile) and its capacity to stick to gastrointestinal mucosa and serious prohibition of pathogenic microorganisms (Collins et al, 1998) ${ }^{[6]}$. Proof put together examination with respect to human and creature models have demonstrated conceivable clinical capacity against numerous ailments as it has demonstrated viable in treating looseness of the bowels, lactose prejudice, displaying antimicrobial and colon malignant growth exercises notwithstanding lessening inside manifestations and fiery entrail infections (Yan and Polk, 2011) ${ }^{[52]}$.

In spite of these medical advantages there are some unfavorable affiliation identified with gut microbes, for example, suggestion in weight, taking care of the movement of colon malignant growth. Anyway we can't sum up a possibility of all the strain, every single strain has a particular capacity that probably won't be relevant to different strains (Lye et al., 2009) ${ }^{[32]}$. The microbiota of every individual has a particular 'bacterial unique finger impression', a layout of it's own species which is not the same as others; by the by there exists some fundamental 57 bacterial species which are basic in each human. Regardless of the promising confirmations the job of probiotics and it's components in human wellbeing just as protected application ought to be additionally explored and the usefulness of gut ought to be comprehended (Williams, 2010) ${ }^{[51]}$.

\section{Probiotics: Definition, action and other related terms}

Probiotics is derived from the Greek word meaning 'for life' probiotics have been defined in 
many ways but the most recent definition given by Fuller “ probiotics are live microbial feed supplement which beneficially effect the host animal by improving microbial balance" (Fuller, 1999) ${ }^{[9,10]}$. Gibson and Roberfroid in 1995 reported the term as food supplements that are indigestiblebut exert beneficial effects on growth and activity on microorganism inhibiting intestine (Gibson and Roberfroid, $1995)^{[14]}$. They are found in form of substrates for probiotics e.g. fructooligosaccharides, the combination of the two i.e. probiotics and prebiotics is called to be either conbiotics/ synbiotics. Recent years have all been about functional foods their development, ingredients casting positive effects on human health (Zeimer and Gibson, 1998) ${ }^{[54]}$.

\section{Microbial species of probiotics and their desirable traits}

Considering their definition the microbial species of probiotics are quite impressive, some of the important representative species of their group Below. In regard to nutrition only the strains of LAB is of significant importance and among them most important genera are Lacto coccus and Bifidobacterium (Holzapfel et al., 2001) ${ }^{[21]}$. LAB are gram negative bacterial species that produce lactic acid as their finished product through carbohydrate fermentation both genus have separate metabolic pathway two of the main species widely used in dairy industry are streptococcus thermophilus and Lactobacillus lactis (Felis and Dellagio, 2007) ${ }^{[8]}$.

\section{Certain desirable traits for probiotics are \\ 1. Tolerance to acid and bile \\ 2. Competitive Adhesion to mucosal and epithelial surfaces \\ 3. Antimicrobial action \\ 4. Bile salt hydrolyze activity.}

The CFU units per gram is an important factor as per standards minimumconcentration of $10 \mathrm{CFU} / \mathrm{ml}$ or gm should be consumed daily for probiotic effect to be transferred to the consumer (Mercenier et al, 2008) ${ }^{[43]}$, (Sarella et al., 2000) ${ }^{[43]}$.

\section{Mechanism of probiotical action}

Probiotic microscopic organisms have various and differing impacts on the host significant instrument that are included are upgrade of Epithelial obstruction, expanded attachment to intestinal mucosa, restraint of pathogen, avoidance of pathogens creation of small scale life forms substances and tweaking resistant framework.

\subsection{Epithelial cells enhancement}

The epithelium layer of digestive system is consistently in vicinity with colon parts and the alterable whole powerful vegetation, intestinal epithelial obstruction assumes significant job in guard component to keep up epithelial respectability and shield life form from condition. The constituent of Safeguard arrangement of hindrance are mucous layer antimicrobial peptides, secretory $\operatorname{IgA}$ and epithelial Intersection attachment complex (Ohland and Macnaughton, 2010).

On account of instance of boundary work disturbance, bacterial and food antigens gets ready to reach submucal layer and prompt fiery reactions which brings about inside ailments (Hopper et al., 2001), (Sartor et al.,2006) "44]. Probiotic microscopic organisms have been widely read for their inclusion in keeping up this obstruction, a few investigations have demonstrated that Quality articulation improving associated with motioning through epithelial is a potential method of upgrading hindrance work for example lactobacilli directed Quality that encodes for adherence Intersection proteins proteins, for example, cadherin and proteins, for example E cadherin and $\beta$-catenin (Anderson et al., 2010) ${ }^{[3]}$. Major sub-atomic constituent mucin glycoprotein of epithelial bodily fluid has been ensnared in wellbeing and infection anticipation. Probiotics have two components one is mucous creation to improve obstruction and disposal of pathogens (Hummel et al, 2012) ${ }^{[24]}$. Ongoing looks into have prompted the way that probiotics starts fix of obstruction work following harm, e.g. expressed by scientist is of E. coli Nissle 1917 (EcN1917) it forestalls upset mucosal layer as well as reestablish entire bodily fluid in $\mathrm{T} 84$ and $\mathrm{CaCo}-2$ cell in colorectal epithelium. This impact is thought about by two junctional cytoplasmic adornment proteins of the Zonula occulents and protein kinase $\mathrm{C}$ reproducing light intersection complex (Zyrek et al., 2007) ${ }^{[55]}$.

Different kinds of epithelial cells take an interest in obstruction intersection, trefoil peptides are created by segment formed cells in respiratory and intestinal tracts known as cup cells emitting fundamental part of bodily fluid and assuming significant job in development and fix notwithstanding mucin impacting bacterial colonization through physical requirements and antimicrobial movement. Cells confining at base of epithelial cells called paneth cells produce wide assortment of peptides and antimicrobial action by and large called as cryptidins or defensins. These components assume significant job in have safeguard against pathogens eg Salmonella (Abreu, Fukata and Arditi, 2005) ${ }^{[1]}$. Probiotics have an another significant impact on boundary intersection which is it's capacity to communicate with commensal creature (works as probiotic substitute) which act through TLR's (Cost like receptor, for example, TLR2 and TLR4) instigating the creation of IL-6 and $\mathrm{KC} 1$ that intercede epithelial regeneration and repressing cell apoptosis which will inevitably prompt ulceration (McCormiick et al.,1998). Another significant impact of probiotics on epithelial obstruction is it's capacity to kill impact of incendiary gut ailment results from these epithelial changes, when built up it prompts further changes exacerbating the previous hindrance issue and hence strengthening the aggravation (Calburgh et al., 2004) ${ }^{[5]}$.

\subsection{Enhanced mucosal grip}

The methodology of mucosal bond is appeased by proteins best organic liquid concentrating on bacterial hold MUB (bodily fluid restricting protein) delivered by Lactobacillus reuteri, these protein are either transmitted or surface proteins for instance either ensured about emphatically to the layer through lipid segment or fixed ardently into cell divider. The authoritative of L. reuteri and L. fermentum to natural liquid has been represented to be conciliated by MapA (mucus adhesio promoting protein) (Ouwehand et al., 2002) ${ }^{[39]}$.

Probiotics like L. plantarum have been represented to induce MUC2 (imparted by flagon cells of little stomachrelated framework and colon) and MUC3 mucin helps in deterrent of pathogenic living creatures to intestinal divider. These recognitions shows that improvement of mucosal layer which overlies intestinal epithelium not withstanding work of microbial confining goals by Lactobacillus sps. gives protection from pathogens (Hirano et al., 2003) ${ }^{[20]}$, (Voltan et al., 2007) ${ }^{[47]}$, (Kim and Ho, 2010) ${ }^{[28]}$.

Observative examinations have shown that host partake 
accordingly of bacterial exercises by substance for instance by growing the estimation of antimicrobial proteins (AMPs) for instance, - and-defensins (have security peptide), ribonucleases, etc. AMP execute the tiny life forms either by enzymatic attack on cell divider or by non enzymatically upsetting bacterial film in following manner, lysozyme hydrolyses the glycosidic linkages of peptidoglycan divider, phospholipaseA2 - phospholipids. These correspondences makes defensins pore in bacterial film realizing aggravation of layer reliability and propelling lysis of microorganisms (ab et al., 2000), (O'neil et al., 1999) ${ }^{[36],(T a k a h a s h i ~ e t ~ a l ., ~ 2001) ~}$ [46], (Ogushi et al., 2001) ${ }^{[38]}$, (Ganz, 2012) ${ }^{[13]}$, (Galo and Hopper, 2012).

\section{Competitive prohibition pathogenic microorganisms}

The term serious prohibition was first authored by Greenberg an American neuroscientist in 1969, referenced in a report with respect to add up to avoidance of Salmonella typhimurium from parasites distributed in 1969 portraying situation in which one types of microscopic organisms contends arduously for receptor locales in intestinal layer than different species. The instruments utilized by these microscopic organisms differs extraordinarily from species to types of lactobacilli and Bifidobacterium demonstrating an expansive range in hindrance of pathogens including E.coli , Salmonella, Helicobacter, rotavirus and so on. Microscopic organisms increase competitive bit of leeway by altering their condition making is less vulnerable for contenders eg incorporate creation of against microbial substances, for example, lactic and acidic corrosive (Nakamura et al.,2012) [35].

\subsection{Immunomodulation}

Human immune system responses to antigens by two different processes innate and adaptive immunity latter being depended on B- cells and $\mathrm{T}$-cells lymphocytes showing specifity towards antigens while former response to general structures common in all microbial cells termed as PAMPs (pathogen associated molecular pattern) (Gomez-Llorente et al., 2010) ${ }^{[15]}$. Probiotic bacteria shows the ability of being intractable with different cells of immune system like dendritic cell, lymphocytes, monocytes/macrophages. Antigens molecules are recognized by PRRs (pattern recognition receptor) and one of the best recognition receptor in our immune system is TLRs (toll like receptor) among all the PRRs, TLRs are expressed in immune and non immune cells (dendritic, lymphocytes etc.) (Lebeer et al.,2010) ${ }^{[29]}$.

A total of 10 proteins are included in TLRs family as human TLR11 has sequencing for non codon thus resulting in lack of production of human TLR11. In human TLR11, TLR2, TLR4, TLR5, TLR6 and TLR10 responds to bacterial surface associated PAMPs whereas TLR3, TLR7, TLR8 and TLR9 responds to nucleic acid based PAMPs on surface of endosomes from viruses and bacteria (Gomez-Llorente et al., 2010) ${ }^{[15]}$. Dimer formed between TLRs and Toll interleukin1 (IL-1) receptor (TIR) leads to formation of adaptive molecules such as myeloid differentiating primary response protein (MyD88) (Wells, 2010). TIR domain containing adaptive protein and TIR domain containing adapter including interferon (TRIF) intimates signaling activation. Commensal and probiotic bacteria along with TLRs and DCs create an overall tolerance state it is clear that TLR9 signaling plays an important role in inflammatory effect of probiotic bacteria.

However, studies have shown that TLR3 and TLR7 also take part in tolerance induced by commensal and probiotic bacteria. Lactobacilli potentially signal through binding TLR2 and TLR6 diacylated membrane anchor of lipoprotein and lipoteichoic acid binds toTLR2 and TLR6 forming dimer with mediation by My288 activation of canonical pathway of NF-k B (Kawai and Akira,2010) ${ }^{[27]}$, (Lebeer et al.,2010) ${ }^{[29]}$, (Wells, 2011) ${ }^{[48]}$.

\section{Effects of probiotics bacteria on dendritic cell, monocytes/ macrophages and lymphocytes}

Dendritic cells (DCs) present antigen cells that assume significant job in bacterial acknowledgment and molding White blood cell reactions. DC have specific capacity of creating cytokines, for example, IL-10 and TGF-by producing administrative Immune system microorganisms and $\operatorname{IgA}$ delivering B cells (Akbari et al.,2001) [2], (Iwasaki and Kelsall,1999) ${ }^{[25]}$, (Williamson et al.,2002) [51]. DC have two different ways of associating with luminal microscopic organisms one being the immediate manner by which it's dendrites are passed between epithelial Intersection into gut lumen (Rescigno et al.,2001) ${ }^{[41]}$. and the backhanded route is in which microbes gain passage through M cells(Stagg $\boldsymbol{e t}$ al.,2003). Impacts of various probiotic microbes is diverse on DC there are tests done on DC got from various parts (entire blood DC, newly detached lamina propria DC, monocytes inferred DC and bone marrow determined DC).

In people probiotic food VSL\#3 is an intense inducer for IL10 in vitro by both blood and lamina propria inferred, patients with IBD when treated with VSL\#3 have expanded degree of IL-10 (Hart et al., 2004) ${ }^{[18]}$. Drake et al. demonstrated that bone marrow DC when brooded with VSL\#3 expanded degree of IL-10 by procedure of ELISA (Drakes et al.,2004) [7]. Each strain has distinctive impact on DC best stamped incendiary activity is appeared by Bifidobacterium strains (B. Longnum, B. Infantis) which alters IL-10 creation of DC (Young et al., 2004) ${ }^{[53]}$. Newly Marine segregated lamina propria DC were found to mystery IL-10 and IL-12 previous being emitted in bigger sums (Rigby et al., 2002) ${ }^{[42]}$. The distinction in impacts of microscopic organisms fluctuates among various strain as well as for eg the Lactobacillus strain L.rhamnosus and L.plantarum actuates low degrees of IL-12 (Braat et al., 2004) ${ }^{[4]}$. Monocytes and tissue macrophages are secondary presenters of antigens to T- cells. Studies have shown that $L$-plantarum increases the level of Il-10 and $L$. Rhamnous promoted production of IFNr, IL-12.Probiotics affects lymphocytes either directly or indirectly based on the stimulation induced by alteration in antigen presenting DC or macrophages (Pathmakanthan et al. 2004) [40], (Miettinen et al., 1998) ${ }^{[34]}$, (He et al., 2002) ${ }^{[19]}$. There are four different types of lymphocytes:

\section{B-lymphocytes}

Probiotic microscopic organisms tweak insusceptible reactions to hurtful antigen through B lymphocytes for eg L. rhamnous was directed to youngsters with intense stomach influenza upgraded humoral reaction by expanding the level in $\operatorname{IgG}, \operatorname{IgA}$ and $\operatorname{IgM}$ emission from lymphocytes. Humoral reaction had upgraded level in youngsters who got L. Casein contrasted with the individuals who got drugs with no theraupetic impact for example fake treatment (Kalia et al., 1992). [26]

NK cells exercises were expanded in spleen cells of BALB/c mice (lab reproduced rodent) when $\mathrm{L}$. casei with probiotic 
dextran were orally regulated to sound volunteers with induced NR cell exercises prompting expanded degree of IL12 (Ogawa et al., 2006) ${ }^{[37]}$.

At the point when probiotic treated DC were co-refined with White blood cells it lead to diminish in level the captivated cells (Immune system microorganism reactions are constrained by communication among DC and Lymphocytes) (Hart et al, 2004) ${ }^{[18]}$. In one trial when monocytes determined DC were refined with L. Rhamnous and their impact on Immune system microorganisms were watched, there was a decline in White blood cell expansion and cytokines creation when $\mathrm{Cd}$ patients were taken care of with $\mathrm{L}$. Rhamnous there was a decrease in IFN-and IL-2 notwithstanding IL-4 (Braat et al., 2004) ${ }^{[4]}$. The tale organic capacity of probiotics is their capacity to impact the resistant cell redistribution helps in improving the competency of epithelial cells to trap $\mathrm{T}$ lymphocytes.

\section{Conclusion}

Probiotics shows an extraordinary potential in the field of remedial application for forestalling different gastrointestinal issue. The effeciency of one bacterial animal groups can't be contrasted with that of another strain. There are as yet many research despite everything taking a shot at system of probiotics as this point is exceptionally tremendous.

This audit paper is with respect to the system of probiotics activity, instruments process incorporates alteration of gut microbiota, immunomodulation, hindrance work and able adherence to mucosa and epithelium. Information on probiotics on invulnerable framework has arrived at an interesting period of research where we will have the option to regulate resistant framework for securing and treatment of turmoil including IBD.

\section{References}

1. Abreu MT, Fukata M, Arditi, M. TLR signaling in the gut in health and disease. The Journal of Immunology. 2005; 174(8), 4453-4460.

2. Akbari O, DeKruyff R, Umetsu DT. Pulmonary dendritic cells producing IL-10 mediate tolerance induced by respiratory exposure to antigen. Nature immunology. 2001; 2(8):725-731.

3. Anderson RC, Cookson AL, McNabb WC, Park Z, McCann MJ, Kelly WJ et al. Lactobacillus plantarum MB452 enhances the function of the intestinal barrier by increasing the expression levels of genes involved in tight junction formation. BMC microbiology. 2010; 10(1):316.

4. Braat $H$, van den Brande J, van Tol E, Hommes D, Peppelenbosch M, van Deventer S et al. Lactobacillus rhamnosus induces peripheral hyporesponsiveness in stimulated CD4+ T cells via modulation of dendritic cell function. The American journal of clinical nutrition. 2004; 80(6):1618-1625.

5. Clayburgh DR, Shen L, Turner JR. A porous defense: the leaky epithelial barrier in intestinal disease. Laboratory investigation. 2004; 84(3):282-291.

6. Collin JK, Thornton G, Sullivan GO. Selection of probiotic strains for human applications. International dairy journal. 1998; 8(5-6):487-490.

7. Drakes M, Blanchard T, Czinn S. Bacterial probiotic modulation of dendritic cells. Infection and immunity. 2004; 72(6):3299-3309.

8. Felis GE, Dellaglio F. Taxonomy of lactobacilli and bifidobacteria. Current issues in intestinal microbiology. 2007; 8(2):44.

9. Fuller R. Probiotics for Farm Animals. In probiotics-A critical review; Tannock, GW Ed, 1999.

10. Fuller R. Probiotics for Farm Animals. In probiotics-A critical review; Tannock, GW Ed., 1999.

11. Gallo RL, Hooper LV. Epithelial antimicrobial defence of the skin and intestine. Nature Reviews Immunology. 2012; 12(7):503-516.

12. Gallo RL, Hooper LV. Epithelial antimicrobial defence of the skin and intestine. Nature Reviews Immunology. 2012; 12(7):503-516.

13. Ganz T. Defensins: antimicrobial peptides of innate immunity. Nature reviews immunology. 2003; 3(9):710720.

14. Gibson GR, Roberfroid MB. Dietary modulation of the human colonic microbiota: introducing the concept of prebiotics. The Journal of nutrition. 1995; 125(6):14011412.

15. Gómez-Llorente C, Munoz S, Gil A. Role of Toll-like receptors in the development of immunotolerance mediated by probiotics. Proceedings of the Nutrition Society. 2010; 69(3):381-389.

16. Gómez-Llorente C, Munoz S, Gil A. 2010. Role of Tolllike receptors in the development of immunotolerance mediated by probiotics. Proceedings of the Nutrition Society. 2010; 69(3):381-389.

17. Guarner F, Malagelada JR. Gut flora in health and disease. The Lancet. 2003; 361(9356):512-519.

18. Hart AL, Lammers K, Brigidi P, Vitali B, Rizzello F, Gionchetti $\mathrm{P}$ et al. Modulation of human dendritic cell phenotype and function by probiotic bacteria. Gut. 2004; 53(11):1602-1609.

19. He F, Morita H, Ouwehand AC, Hosoda M, Hiramatsu M, Kurisaki JI et al. Stimulation of the secretion of proinflammatory cytokines by Bifidobacterium strains. Microbiology and immunology. 2002; 46(11):781-785.

20. Hirano J, Yoshida T, Sugiyama T, Koide N, Mori I, Yokochi $\mathrm{T}$ et al. The effect of Lactobacillus rhamnosus on enterohemorrhagic Escherichia coli infection of human intestinal cells in vitro. Microbiology and immunology, 47(6), 405-409.

21. Holzapfel WH, Haberer P, Geisen R, Björkroth J, Schillinger U. Taxonomy and important features of probiotic microorganisms in food and nutrition. The American journal of clinical nutrition. 2001; 73(2):365s373 s.

22. Hooper LV, Wong MH, Thelin A, Hansson L, Falk PG, Gordon JI et al. Molecular analysis of commensal hostmicrobial relationships in the intestine. Science. 2001; 291(5505):881-884.

23. Hotel ACP, Cordoba A. Health and nutritional properties of probiotics in food including powder milk with live lactic acid bacteria. Prevention. 2001; 5(1):1-10.

24. Hummel S, Veltman K, Cichon C, Sonnenborn U, Schmidt MA. Differential targeting of the E-cadherin $/ \beta$ catenin complex by Gram-positive probiotic lactobacilli improves epithelial barrier function. Appl. Environ. Microbiol. 2012; 78(4):1140-1147.

25. Iwasaki A, Kelsall BL. Freshly isolated Peyer's patch, but not spleen, dendritic cells produce interleukin 10 and induce the differentiation of $\mathrm{T}$ helper type 2 cells. The Journal of experimental medicine. 1999; 190(2):229-240.

26. Kaila M, Isolauri E, Soppi E, Virtanen E, Laine S, Arvilommi $\mathrm{H}$ et al. Enhancement of the circulating antibody secreting cell response in human diarrhea by a human Lactobacillus strain. Pediatric research. 1992; 32(2):141-144. 
27. Kawai T, Akira S. The role of pattern-recognition receptors in innate immunity: update on Toll-like receptors. Nature immunology. 2010; 11(5):373.

28. Kim YS, Ho SB. Intestinal goblet cells and mucins in health and disease: recent insights and progress. Current gastroenterology reports. 2010; 12(5):319-330.

29. Lebeer S, Vanderleyden J, De Keersmaecker SC. Host interactions of probiotic bacterial surface molecules: comparison with commensals and pathogens. Nature Reviews Microbiology. 2010; 8(3):171-184.

30. Liong MT. Safety of probiotics: translocation and infection. Nutrition reviews. 2008; 66(4):192-202.

31. Liong MT (Ed.). Probiotics: biology, genetics and health aspects Springer Science \& Business Media, 2011; (21).

32. Lye HS, Kuan CY, Ewe JA, Fung WY, Liong MT. The improvement of hypertension by probiotics: effects on cholesterol, diabetes, renin, and phytoestrogens. International journal of molecular sciences. 2009; 10(9):3755-3775.

33. Mercenier A, Lenoir-Wrjnkoop I, Sanders ME. Physiological and functional properties of probiotics. Journal of Milk Science and Biotechnology. 2008; 26(1):53-57.

34. Miettinen M, Matikainen S, Vuopio-Varkila J, Pirhonen J, Varkila K, Kurimoto $\mathrm{M}$ et al. Lactobacilli and streptococci induce interleukin-12 (IL-12), IL-18, and gamma interferon production in human peripheral blood mononuclear cells. Infection and Immunity. 1998; 66(12):6058-6062.

35. Nakamura S, Kuda T, An C, Kanno T, Takahashi H, Kimura B et al. Inhibitory effects of Leuconostoc mesenteroides 1RM3 isolated from narezushi, a fermented fish with rice, on Listeria monocytogenes infection to Caco-2 cells and A/J mice. Anaerobe. 2012; 18(1):19-24.

36. O'Neil DA, Porter EM, Elewaut D, Anderson GM, Eckmann L, Ganz $\mathrm{T}$ et al. Expression and regulation of the human $\beta$-defensins hBD-1 and hBD-2 in intestinal epithelium. The Journal of Immunology. 1999; 163(12):6718-6724.

37. Ogawa T, Asai Y, Tamai R, Makimura Y, Sakamoto H, Hashikawa $\mathrm{S}$ et al. Natural killer cell activities of synbiotic Lactobacillus casei ssp. casei in conjunction with dextran. Clinical \& Experimental Immunology. 2006; 143(1):103-109.

38. Ogushi KI, Wada A, Niidome T, Mori N, Oishi K, Nagatake $\mathrm{T}$ et al. Salmonella enteritidis FliC (flagella filament protein) induces human $\beta$-defensin-2 mRNA production by Caco-2 cells. Journal of Biological Chemistry. 2001; 276(32):30521-30526.

39. Ouwehand AC, Salminen S, Tölkkö S, Roberts P, Ovaska J, Salminen E et al. Resected human colonic tissue: new model for characterizing adhesion of lactic acid bacteria. Clin. Diagn. Lab. Immunol. 2002; 9(1):184-186.

40. Pathmakanthan S, Li CK, Cowie J, Hawkey CJ. Lactobacillus plantarum 299: beneficial in vitro immunomodulation in cells extracted from inflamed human colon. Journal of gastroenterology and hepatology. 2004; 19(2):166-173.

41. Rescigno M, Urbano M, Valzasina B, Francolini M, Rotta G, Bonasio R et al. Dendritic cells express tight junction proteins and penetrate gut epithelial monolayers to sample bacteria. Nature immunology. 2001; 2(4):361367.
42. Rigby R, Kamm MA, Knight SC, Hart AL, Stagg AJ. Pathogenic bacteria stimulate colonic dendritic cells to produce pro-inflammatory IL-12 while the response to probiotic bacteria is to produce anti-inflammatory IL-10. In Gut. British med assoc house, tavistock square, london wc1h 9jr, england: british med journal publ group. 2002; 50:A70-A70

43. Saarela M, Mogensen G, Fonden R, Mättö J, MattilaSandholm T. Probiotic bacteria: safety, functional and technological properties. Journal of biotechnology. 2000; 84(3):197-215.

44. Sartor RB. Mechanisms of disease: pathogenesis of Crohn's disease and ulcerative colitis. Nature clinical practice Gastroenterology \&hepatology. 2006; 3(7):390407.

45. Stagg AJ, Hart AL, Knight SC, Kamm MA. The dendritic cell: its role in intestinal inflammation and relationship with gut bacteria. Gut. 2003; 52(10):1522-1529.

46. Takahashi A, Wada A, Ogushi KI, Maeda K, Kawahara $\mathrm{T}$, Mawatari $\mathrm{K}$ et al. Production of $\beta$-defensin- 2 by human colonic epithelial cells induced by Salmonella enteritidis flagella filament structural protein. FEBS letters. 2001; 508(3):484-488.

47. Voltan S, Castagliuolo I, Elli M, Longo S, Brun P, D'Incà $\mathrm{R}$ et al. Aggregating phenotype in Lactobacillus crispatus determines intestinal colonization and TLR2 and TLR4 modulation in murine colonic mucosa. Clin. Vaccine Immunol. 2007; 14(9):1138-1148.

48. Wells JM. Immunomodulatory mechanisms of lactobacilli. In Microbial cell factories BioMed Central. 2011; 10(1):S17.

49. WHO F. Report on Joint FAO. WHO Expert Consultation, 2001.

50. Williams NT. Probiotics. American Journal of HealthSystem Pharmacy. 2010; 67(6):449-458.

51. Williamson E, Bilsborough JM, Viney JL. Regulation of mucosal dendritic cell function by receptor activator of NF- $\mathrm{B}$ (RANK)/RANK ligand interactions: impact on tolerance induction. The Journal of Immunology. 2002; 169(7):3606-3612.

52. Yan F, Polk DB. Probiotics and immune health. Curr. Opin. Gastroenterol, 2011.

53. Young SL, Simon MA, Baird MA, Tannock GW, Bibiloni R, Spencely $\mathrm{K}$ et al. Bifidobacterial species differentially affect expression of cell surface markers and cytokines of dendritic cells harvested from cord blood. Clin. Diagn. Lab. Immunol. 2004; 11(4):686-690.

54. Ziemer CJ, Gibson GR. An overview of probiotics, prebiotics and synbiotics in the functional food concept: perspectives and future strategies. International Dairy Journal. 1998; 8(5-6):473-479.

55. Zyrek AA, Cichon C, Helms S, Enders C, Sonnenborn U, Schmidt MA et al. Molecular mechanisms underlying the probiotic effects of Escherichia coli Nissle 1917 involve ZO-2 and $\mathrm{PKC} \zeta$ redistribution resulting in tight junction and epithelial barrier repair. Cellular microbiology. 2007; 9(3):804-816. 